\title{
MEMÓRIA DE ELEFANTE DE ANTÓNIO LOBO ANTUNES: O TEXTO EM DIÁLOGO COM AS ARTES VISUAIS
}

Sílvia Herkenhoff Carijó*

RESUMO: O presente trabalho busca refletir sobre a questão da intersemioticidade em Memória de elefante de António Lobo Antunes, romance em que o auto trava diversos diálogos com a obra de alguns pintores. Mais especificamente, procuramos analisar como alguns pintores e quadros são introduzidos na narrativa contribuindo para sua dinâmica composicional.

PALAVRAS-CHAVE: Memória de elefante; Lobo Antunes; intersemioticidade.
* silviacarijo@gmail.com

Mestranda do Programa de Pós-Graduação em Estudos de Literatura da UFF.

ABSTRACT: This article examines the issue of intersemioticity in Memória de Elefante by Lobo Antunes, where the author establishes dialogues with the work of several painters. More particularly, we try to analize in what manner some painters and paintings are inserted into the text and how they contribute to its composition.

KEYWORDS: Memória de elefante; Lobo Antunes; intersemioticity. 


\section{MEMÓRIA DE ELEFANTE}

Memória de elefante é o primeiro romance de Lobo Antunes. Lançado em Portugal em 1979, o livro narra os eventos de um dia da vida de um psiquiatra divorciado que, apesar do fracasso de seu casamento, ainda ama a ex-mulher, com quem tem duas filhas. O médico sofre por estar longe de sua família e se encontra em um momento confuso, sentindo-se débil frente aos obstáculos da vida e passando por uma crise existencial. O leitor toma conhecimento não apenas dos acontecimentos desse curto período, mas também de diversas recordações e pensamentos do protagonista que ocorrem nesse espaço de tempo. A confusão instaurada na cabeça do personagem pode ser sentida através da narrativa caótica e pessimista.

É interessante notar que a vida do protagonista se assemelha à do próprio Lobo Antunes: ambos estiveram em Angola durante a guerra colonial portuguesa, moram em Lisboa e são psiquiatras, sendo o personagem considerado, por isso, o alter ego do próprio autor. Memória de elefante fez tanto sucesso que Lobo Antunes pôde deixar a carreira de médico e dedicar-se à literatura.

\section{INTERSEMIOTICIDADE EM ANTÓNIO LOBO ANTUNES}

A obra de António Lobo Antunes é permeada por diversas referências provenientes das mais diferentes áreas de conhecimento. Muito comum é o diálogo travado com pintores, na maioria das vezes citados pelo nome. Essa peculiaridade da escrita de Lobo Antunes requer que o leitor esteja constantemente acessando algum tipo de informação armazenado em sua memória e traz elementos característicos das artes visuais para o texto.

Em artigo intitulado "Danças com Letras - Intersemioticidade em António Lobo Antunes”, Maria Alzira Seixo discorre sobre o processo de intersemioticidade em diversos romances do autor. Ela ressalta que a intersemioticidade é um dos processos mais característicos da cultura contemporânea e que esse jogo intersemiótico manifesta-se com particular relevância em Lobo Antunes. Ela coloca que, na obra do autor o jogo ocorre não só com a arte em geral, mas também com sistemas de significação marginais à consagração artística (como marcas comerciais).

Em seu artigo ela pretende assinalar:

o jeito de intersecção artística que orienta alguns aspectos determinantes do seu modo de escrever, tornando decisivamente presentes, na orgânica e na dinâmica composicional aspectos específicos de outras artes e diversas perspectivações estéticas, assim como interferências de textos de outros domínios da criação, dos quais poderemos salientar, como mais significativos, os da música, da pintura, do cinema, da dança, da fotografia e da arquitetura.
1. SEIXO. Danças com Letras Intersemioticidade em Anto Lobo Antunes, p. 282 
2. SEIXO. Danças com Letras Intersemioticidade em António Lobo Antunes, p. 289.
A autora afirma que a intersemioticidade em Lobo Antunes não funciona apenas como ilustração do literário, e sim como uma criação de tipo intersticial, de forma a estar constantemente se movimentando pelos outros domínios artísticos e por outras áreas.

Maria Alzira Seixo ressalta três aspectos fundamentais da escrita do autor, dos quais dois são mais relevantes para nossa discussão. O primeiro é precisamente o "da composição de tipo intersticial, isto é, da conjunção semântica de diferenças, da verificação e construção de declives e falhas no universo romanesco, da escrita de interrupçoes do discurso, de brancos, de buracos no texto, de interdições ao dizer". ${ }^{2}$ Ainda segundo a autora, a arte funciona como um complemento da escrita, e a intersemioticidade salienta o abandono da unicidade na criação.

Lobo Antunes traz para seu texto elementos específicos das obras de diversos pintores. Cria, assim, uma atmosfer particular que não poderia ser alcançada de outra forma, uma vez que tais obras portam consigo toda uma carga expressiva própria. Desse modo, quando a memória dessas pinturas é ativada, um quadro vívido é despertado, envolvendo o leito naquela atmosfera. Admitindo que a sua arte tem limites, o autor, de certa forma, transgride fronteiras ao trazer para o seu domínio esta arte irmã, que pode completar possíveis faltas.
O segundo aspecto que Seixo ressalta está relacionado com a ênfase aos olhos. A autora liga a pintura e o cinema, tão presentes em Lobo Antunes, à dominância do olhar, afirmando que as artes plásticas vêm preencher a imagística do discurso.

OS QUADROS E PINTORES EM MEMÓRIA DE ELEFANTE

O diálogo com pintores em Memória de elefante proporciona uma extensa discussão, apresentando inúmeros exemplos. Ao longo do romance o autor cita pintores e escultores tais como: Cimabue, Delvaux, Vermeer, Giacometti, Velázquez, Rembrandt, Henry Moore, Cranach, Soutine, Degas, Picasso, Cézanne, Botticelli, Matisse, Van Gogh, Miró, entre outros.

Como Lobo Antunes não costuma fazer referência a quadros específicos nas passagens em que menciona pintores em seu romance, a identificação de uma obra que pareça estar de acordo com a respectiva passagem é dificultada. Por isso, parte de nosso trabalho foi selecionar pinturas que pareciam condizentes com os trechos analisados, tendo tal escolha se tornado, em alguns casos, realmente difícil (como ficará claro em um exemplo adiante). O segundo passo foi pensar como os quadros e pintores aludidos por Lobo Antunes estariam ligados à narrativa.

Algumas passagens selecionadas por Maria Alzira Seixo em seu já citado artigo nos servem como início de discussão. 
3. ANTUNES. Memória de elefante, p. 10.
A autora seleciona vários trechos da obra em questão em que o autor se refere a pintores diversos, como nos mostra o exemplo retirado de uma das primeiras páginas do romance:

um dos projectos secretos do médico consistia em saltar a pés juntos para dentro dos quadros de Cimabue e dissolver-se nos ocres desbotados de uma época ainda não inquinada pelas mesas de fórmica e pelas pagelas da Sãozinha: lançar mergulhos rasantes de perdiz, mascarado de serafim nédio, pelos joelhos de virgens estranhamente idênticas às mulheres de Delvaux, manequins de espanto nu em gares que ninguém habita. ${ }^{3}$

Segundo a autora, pode-se constatar aqui

uma ekphrasis sugestiva de um quadro de Paul Delvaux, The Village of Mermaids, em cuja leitura escrita no texto vários motivos da obra antuniana se concentram: a mulher, estática e passiva, em atitude de silêncio e espera; a notação do corpo, cingido, onde avultam as mãos, os joelhos, os seios, os cabelos, mas sobretudo os olhos, abertos, fixos e vazios; a reiteração das figuras e das atitudes; o ambiente espectral urbano e paisagístico; o alheamento das figuras, coisificadas em estátuas; a multiplicidade das portas, todas fechadas; o mobiliário insólito para o ambiente (cadeiras de estilo ao ar livre); e a visão longínqua do mar, onde a possível metamorfose das mulheres inactivas, tornadas sereias em atitudes dinâmicas na praia que se avista, permite a conjectura de imersão noutro ambiente ou numa espécie de voo. Ao fundo do primeiro plano do quadro (é do quadro de Delvaux que estou a falar), do lado urbano e junto à parede que os separa da praia, avista-se a figura de um homem, de dimensões reduzidas, quando termina a fila das mulheres que se sentam, perfiladas, e ele está de pé virando-lhes as costas, sugerindo-se que abala e abandona a cena. A monocromia é quase total, dado que o azul esverdeado e sombrio, contíguo à ideia de céu e de mar, apenas se abre nos ocres do chão e num branco ocasional do muro ensolarado. ${ }^{4}$

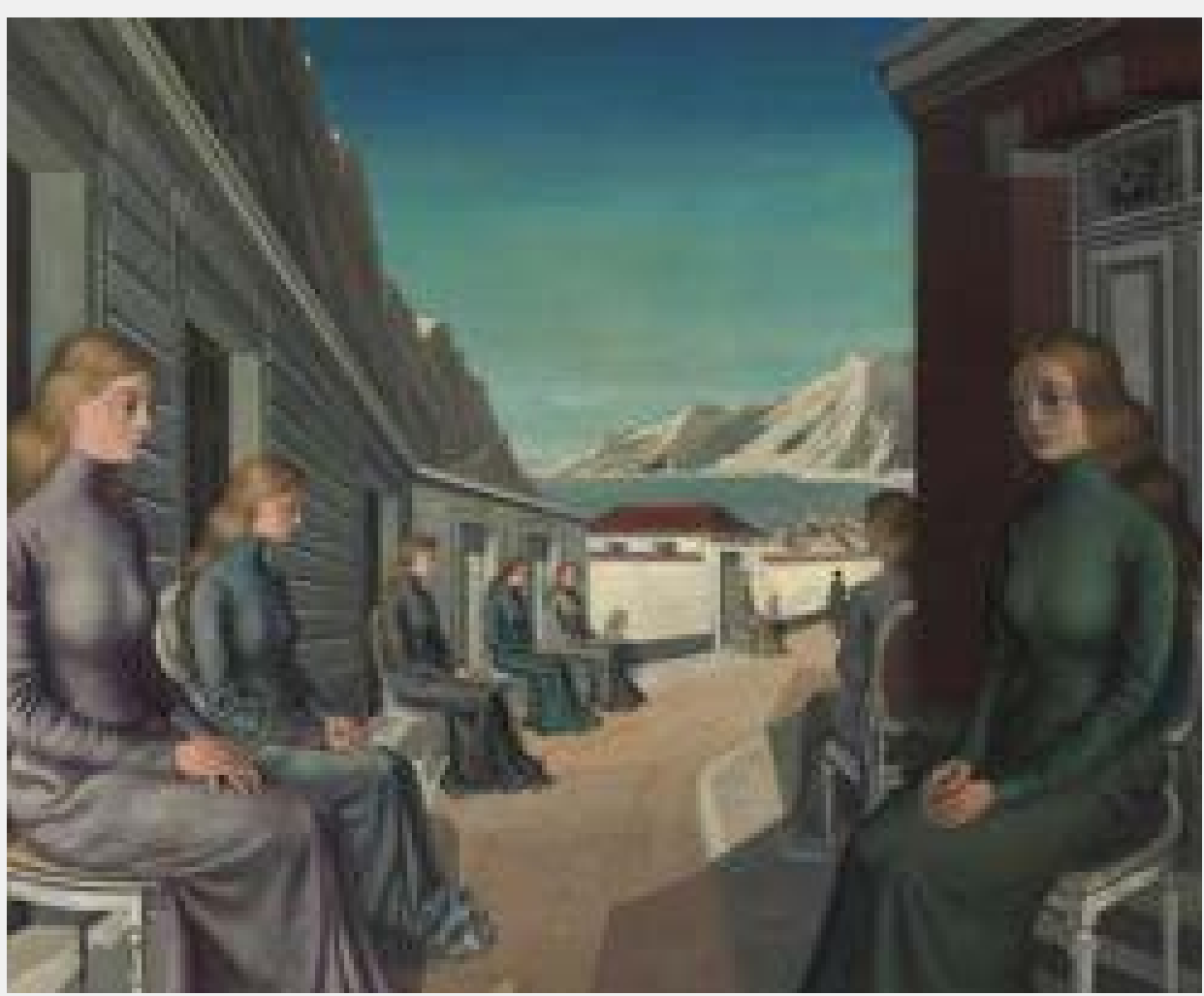

FIGURA 1
4. SEIXO. Danças com Letras Intersemioticidade em António Lobo Antunes, p. 287.

FIGURA 1

Paul Delvaux: The Village of Mermaids 
5. ANTUNES. Memória de elefante, p. 84.

Maria Alzira Seixos continua a sua argumentação citando alguns exemplos provenientes da pintura, mostrando como ela vem a constituir ambientes ou participar da caracterização de relações, e ressalta três passagens onde esta forma de arte aparece de modo a enriquecer os processos descritivos. Em relação à escultura, ela coloca que a mesma tem uma intervenção esporádica em Memória de elefante com Henry Moore e Giacometti. A seguir, alguns desses trechos são desdobrados.

Muito comuns são descrições da cidade de Lisboa ao longo do romance. A primeira passagem selecionada é um trecho em que o narrador descreve um momento de interação com a cidade onde vive: "quando Lisboa, num gesto meditativo de lagosta de viveiro, lhe apertava as pinças em torno dos tendões do pescoço, e casas, árvores, praças e ruas penetravam tumultuosamente na sua cabeça à moda de um quadro de Soutine dançando um charleston carnívoro e frenético." ${ }^{5}$

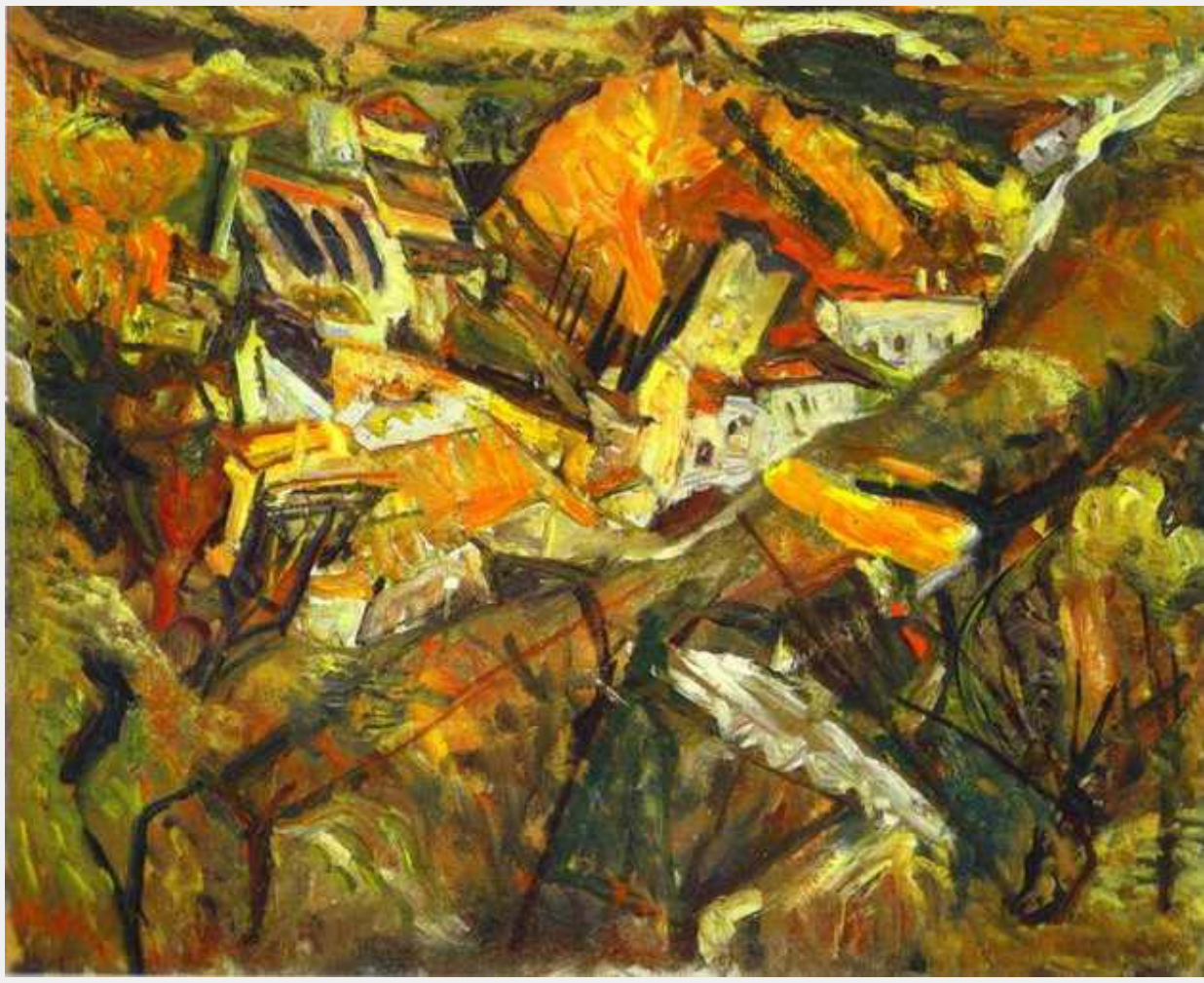

FIGURA 2

No quadro, podemos ver casas, árvores e todo cenário da cidade como que serem engolidos por um centro, ou como se estivessem fazendo o movimento de um ciclone. Se imaginarmos a cabeça do personagem como esse centro, podemos ver as “casas, árvores, praças e ruas" penetrarem "tumultuosamente na sua cabeça”. Assim como a sua vida está confusa, assim também as imagens da cidade penetram tumultuosamente em sua cabeça. Tudo parece estar sendo engolido, a sensação não é apenas de confusão, parece também que o mundo está
FIGURA 2

Chaïm Soutine: Paysage de Céret 
6. ANTUNES. Memória de elefante p. 157.

7. Napoleão é como ele se refere à enfermeira-chefe, que "no seu gabinete de Dr. Mabuse, recolocava a dentadura postiça nas gengivas com a majestad de Napoleăo coroando-se a $2006: 14)$. Como se 2006:14). Como se pode ver, o texto de António Lobo Antunes e permeado tamberm por referências históricas cinematográficas. desabando, e o quadro transmite essa sensação de caos. Assim como o exemplo anterior, comentado por Maria Alzira Seixo, essa passagem pode ser tomada como uma ekphrasis. O autor, aqui, ainda faz conexão com outra arte, que também está bastante presente em sua obra, ao acionar a dança e trazer o ritmo frenético do charleston.

A segunda passagem selecionada também é um processo descritivo: "telhados onde florescem plantações de antenas de televisão idênticas a arbustos de Miró”. ${ }^{6}$

Como mencionado anteriormente, António Lobo Antunes cita, na maioria das vezes, nomes de pintores sem fazer referência a nenhum quadro específico, tornando muitas vezes difícil a identificação daquele por parte do leitor. E aqui temos um desses exemplos. O quadro de Miró intitulado The Garden contém arbustos, mas apresenta uma estética mais harmoniosa do que, por exemplo, o quadro, do mesmo pintor, intitulado The Nightingale's Song at Midnight and the Morning Rain. O traço que costumamos associar a Miró está possivelmente mais de acordo com o último exemplo e, considerando se tratar de "plantações de antenas de televisão" em uma cidade, poderia se dizer que o traço menos harmonioso, mais caótico, estaria mais de acordo com a descrição no romance. A narrativa também nos proporciona outra interpretação, pois poderia apenas estar trazendo a estética mais comumente ligada a Miró, como no quadro The Nightingale's Song at Midnight and the Morning Rain, ou então mesclando essa estética aos arbustos representados em The Garden. Assim, formaríamos uma imagem em que as formas dos arbustos do The Garden seriam somadas à estética do quadro The Nightingale's Song at Midnight and the Morning Rain.

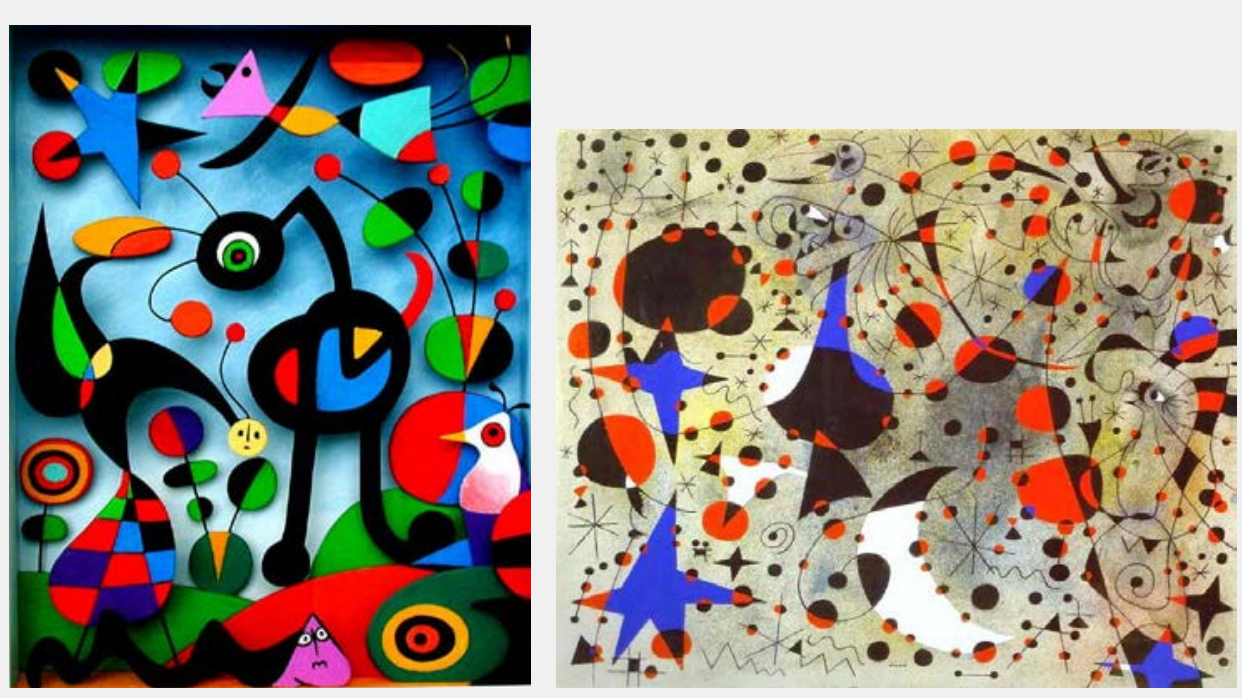

FIGURA 3

Além dos vários exemplos trazidos por Maria Alzira Seixo, António Lobo Antunes faz referência a diversos outros pintores em Memória de elefante. Ao descrever as senhoras no seu local de trabalho, o narrador lembra dos quadros de Vermeer:

Algumas velhas, que as castanholas bocais de Napoleão ${ }^{7}$ haviam despertado de letargias de pedra, chinelavam ao acaso de cadeira em cadeira idênticas a pássaros sonolentos em busca do arbusto onde ancorar: o médico tentava em vão decifrar

\section{FIGURA 3}

Joan Miró: The Garden e The Nightingale's Song at Midnight and the Morning Rain
EM TESE
BELO HORIZONTE
v. 19
N. 2
AG0.-OUT. 2013
CARIIÓ. Memória de elefante de António Lobo Antunes [...]
p. $84-94$ 
8. ANTUNES. Memória de elefante, p. 15. Grifo meu.

\section{FIGURA 4}

Joan Miró: The Garden e The

Nightingale's Song at Midnight and the Morning Rain nas espirais das suas rugas, que lhe lembravam as misteriosas redes de fendas dos quadros de Vermeer. ${ }^{8}$

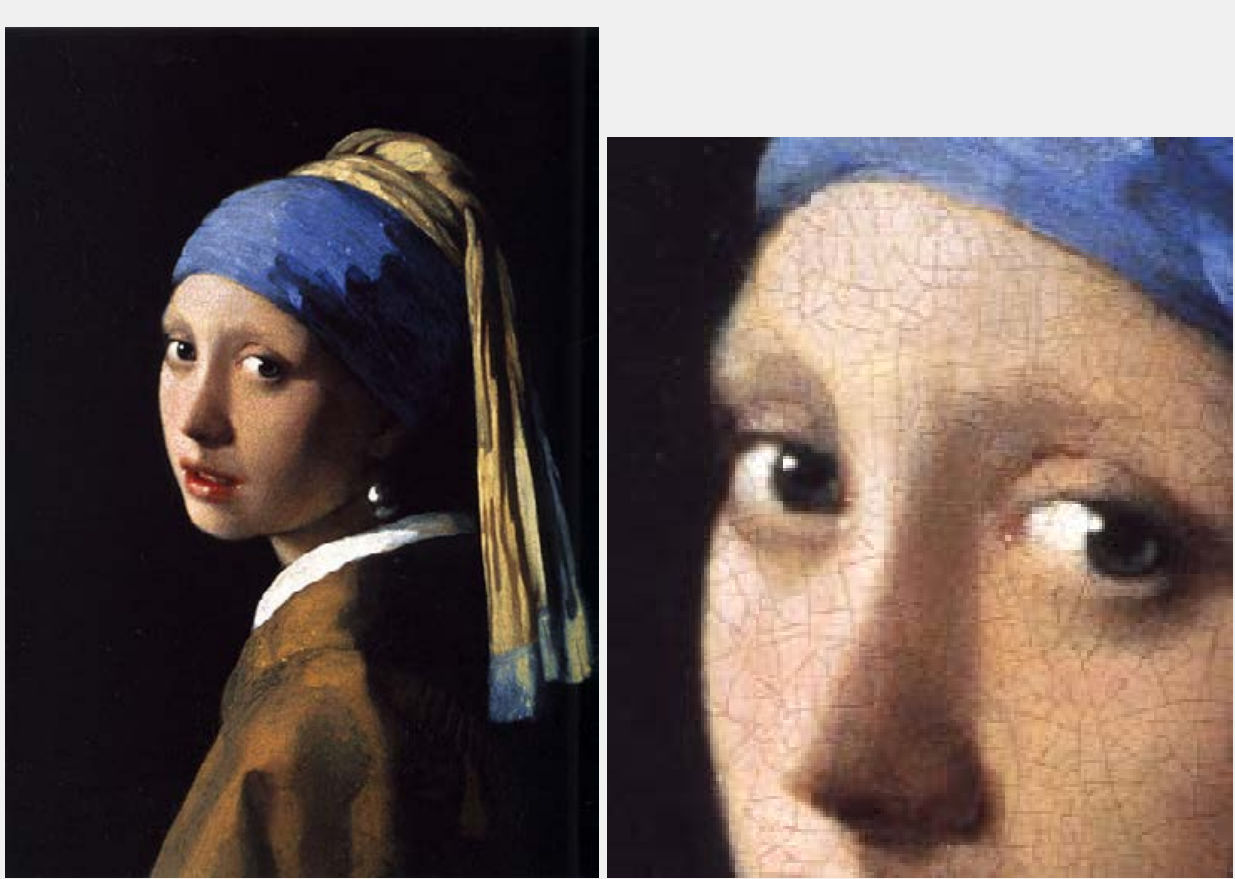

FIGURA 4

Nos quadros de Vermeer, podemos ver as "redes de fendas" como as redes de fendas provocadas pelo tempo. O mistério fica por conta do próprio mistério do tempo e da obra de arte.

O autor descreve, aqui, um ambiente completamente desolado, que é a clínica psiquiátrica onde trabalha, e evoca um pintor que não costumamos relacionar com um ambiente deste tipo, causando, talvez, até certo desconforto e o questionamento do motivo desta evocação. Por outro lado, cria-se um contraste do quadro como o que vemos acima, da eternamente jovem menina, com o ambiente desolado das velhas sem perspectiva de vida, tendo como único fim a morte. As fendas no quadro da obra de arte eterna contrapõem-se à temporalidade da vida no exemplo das velhas com rugas. Na obra de Vermeer, apesar de as fendas marcarem o quadro, a jovem permanecerá eternamente jovem.

Passando para o próximo exemplo, podemos notar que, em certos momentos, o autor cita certos pintores para se apropriar de alguma característica muito marcante dos mesmos, como é o caso de umas das passagens em que cita Giacometti: "O corpo dela permanecia jovem e leve apesar dos partos, e o rosto mantinha intactos a pureza dos malares e o nariz perfeito de uma adolescência triunfal: junto dessa beleza esguia de Giacometti maquilhado".

Alberto Giacometti, pintor e escultor, tem talvez como característica mais marcante rostos e corpos esguios, como podemos ver nos exemplos da escultura e do quadro a seguir:
9. ANTUNES. Memória de elefante, p. 22-3. 
FIGURA 5

Alberto Giacometti: Femme à l'épaule casse e Annette noire

\section{ANTUNES. Memória de elefante, p. 131.}

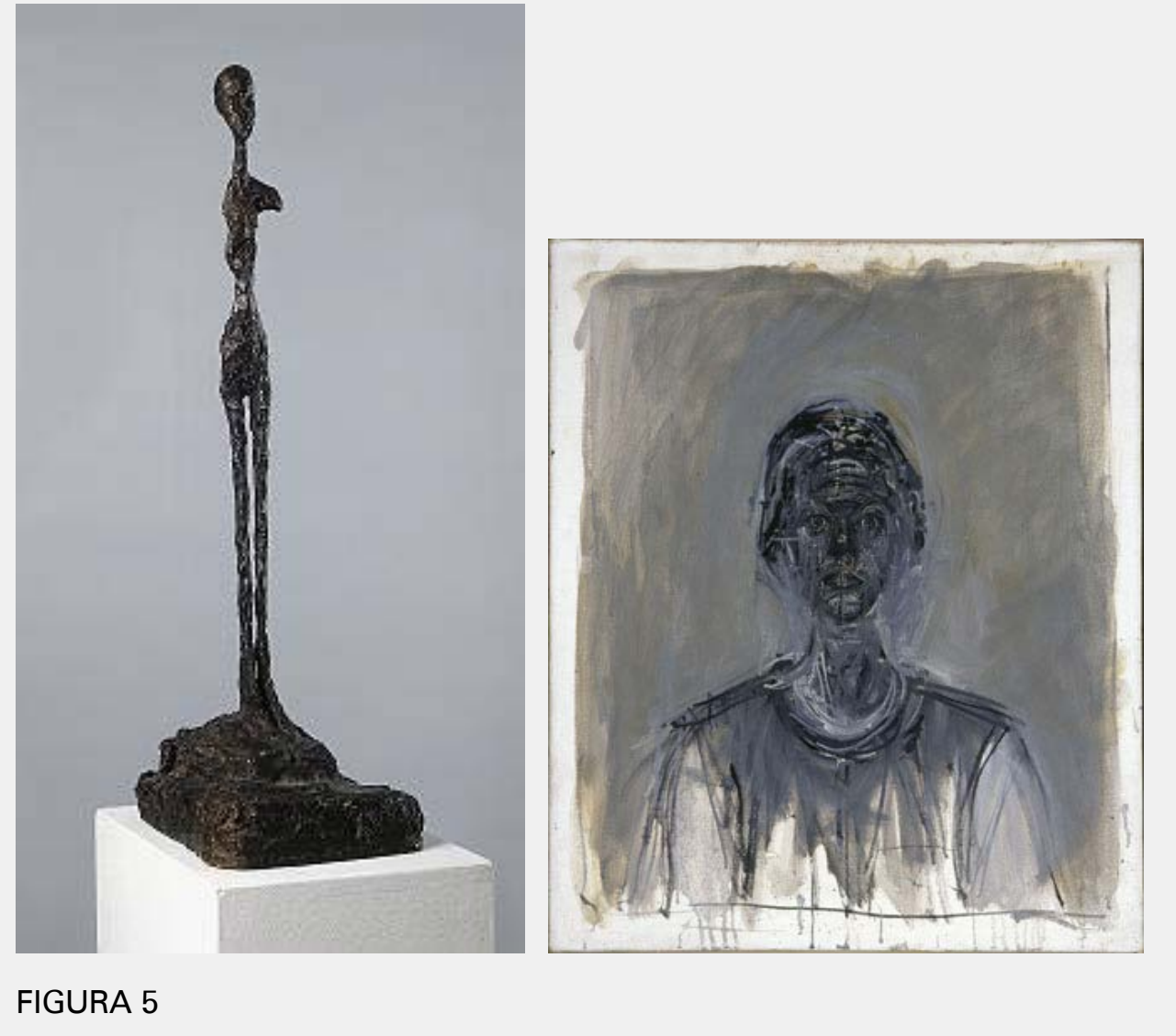

Sendo assim, ninguém melhor para representar a beleza esguia a que o autor se refere do que o próprio Giacometti. Também a essa economia do escultor se refere novamente o autor em outra passagem: "se tudo isto é limpo, claro, directo, sem precisão de bonitezas, enxuto como um Giacomett numa sala vazia e tão simplesmente eloquente como ele". ${ }^{10}$

\section{O HOSPITAL PSIQUIÁTRICO}

O último exemplo de diálogo com outras artes que apresentaremos é uma referência à arquitetura: o Hospital Miguel Bombarda, onde o médico trabalha. A disposição física do prédio está constantemente presente em descrições de seu local de trabalho, e é justamente com esse hospital que o autor abre seu romance de estreia: "O Hospital em que trabalhava era o mesmo a que muitas vezes na infância acompanhara o pai: antigo convento de relógio de junta de freguesia na fachada, pátio de plátanos oxidados, doentes de uniforme vagabundeando ao acaso tontos de calmantes". ${ }^{11}$

E em outro trecho:

Tratava-se de perguntas a que não sabia responder claramente e o deixavam confuso e aflito consigo, eriçado de interrogações, de dúvidas, de escrúpulos: quando ali entrara no início do internato e o levaram a visitar o decrépito edifício medonho do hospital de que apenas conhecia até então o pátio e a fachada, cuidara-se num casarão de província habitado pelos fantasmas de Fellini: escorados por muros que escorriam de humidade pegajosa, débeis mentais quase nus masturbavam-se em movimentos de balanço voltando para ele o espanto desdentado das bocas; homens de cabeça rapada estendiam-se ao sol, mendigavam ou acendiam cigarros, cujas mortalhas eram pedaços de jornal escurecidos de cuspo; velhos apodreciam nos colchões podres, vazios de pala-
11. ANTUNES. Memória de elefante, p. 9. 
12. ANTUNES. Memória de elefante, p. 47. vras, ocos de ideias, vegetais trêmulos durando apenas; e havia o redondel da $8^{a}$ enfermaria e as pessoas contidas pelos derros, símios vagarosos moendo frases desconexas, a encalharem ao acaso nos buracos de curro em que dormiam. ${ }^{12}$

Apesar de ter acompanhado o seu pai ao hospital repetidas vezes quando pequeno, o protagonista afirma que, antes de ter entrado para o internato, só conhecia o pátio e a fachada do prédio, dando a entender que só havia tido um contato superficial com a instituição. A partir do momento que entra lá como profissional, passa a ter uma noção mais clara de como é sua real atmosfera de trabalho e de como vivem os doentes ali internados. Aos poucos, vai descobrindo que o ambiente do hospital é como seu edifício: decrépito e medonho. Esses adjetivos também servem perfeitamente para todo o restante que lá se encontra, principalmente para a situação dos internados. Assim, parcialmente através da arquitetura do hospita psiquiátrico, o autor faz a sua crítica à instituição psiquiátrica, que permeia toda a narrativa. E continua:

E aqui estou eu, disse-se o médico, a colaborar não colaborando com a continuação disto, com a pavorosa máquina doente da Saúde Mental trituradora no ovo dos germenzinhos de liberdade que em nós nascem sob a forma canhestra de um protesto inquieto, pactuando mediante o meu silêncio, o ordenado que recebo, a carreira que me oferecem: como resistir de dentro, quase sem ajuda, à inércia eficaz e mole da psiquiatria institucional, inventora da grande linha branca de separar a "normalidade" da "loucura" através de uma complexa e postiça rede de sintomas, da psiquiatria como grosseira alienação, como vingança dos castrados contra o pénis que não têm, como arma real da burguesia a que por nascença pertenço e que se torna tão difícil renegar, hesitando como hesito entre o imobilismo cômodo e a revolta penosa, cujo preço se paga caro porque se não tiver pais quem virá querer, à Roda, perfilhar-me? ${ }^{13}$

O hospital parece funcionar como uma prisão, - o que pode ser verificado através de sua estrutura - retirando a liberdade das pessoas e separando os normais dos loucos.

\section{CONSIDERAÇÕES FINAIS}

A partir dos exemplos discutidos, pudemos ver algumas formas através das quais Lobo Antunes incorpora aspectos ligados às artes visuais ao seu texto. Assim como Maria Alzira Seixo coloca, os exemplos nos mostram como características de outras artes estão presentes no texto do autor fazendo realmente parte da dinâmica composicional de sua obra. No presente trabalho, tivemos a chance de observar apenas algumas relações com as artes plásticas e a arquitetura, apesar de a obra de Lobo Antunes dialogar também com outras artes e domínios, como já ressaltado.
13. ANTUNES. Memória de elefante, p. 47-8. 
FIGURA 6

Hospital Miguel Bombarda (Imagem 1)

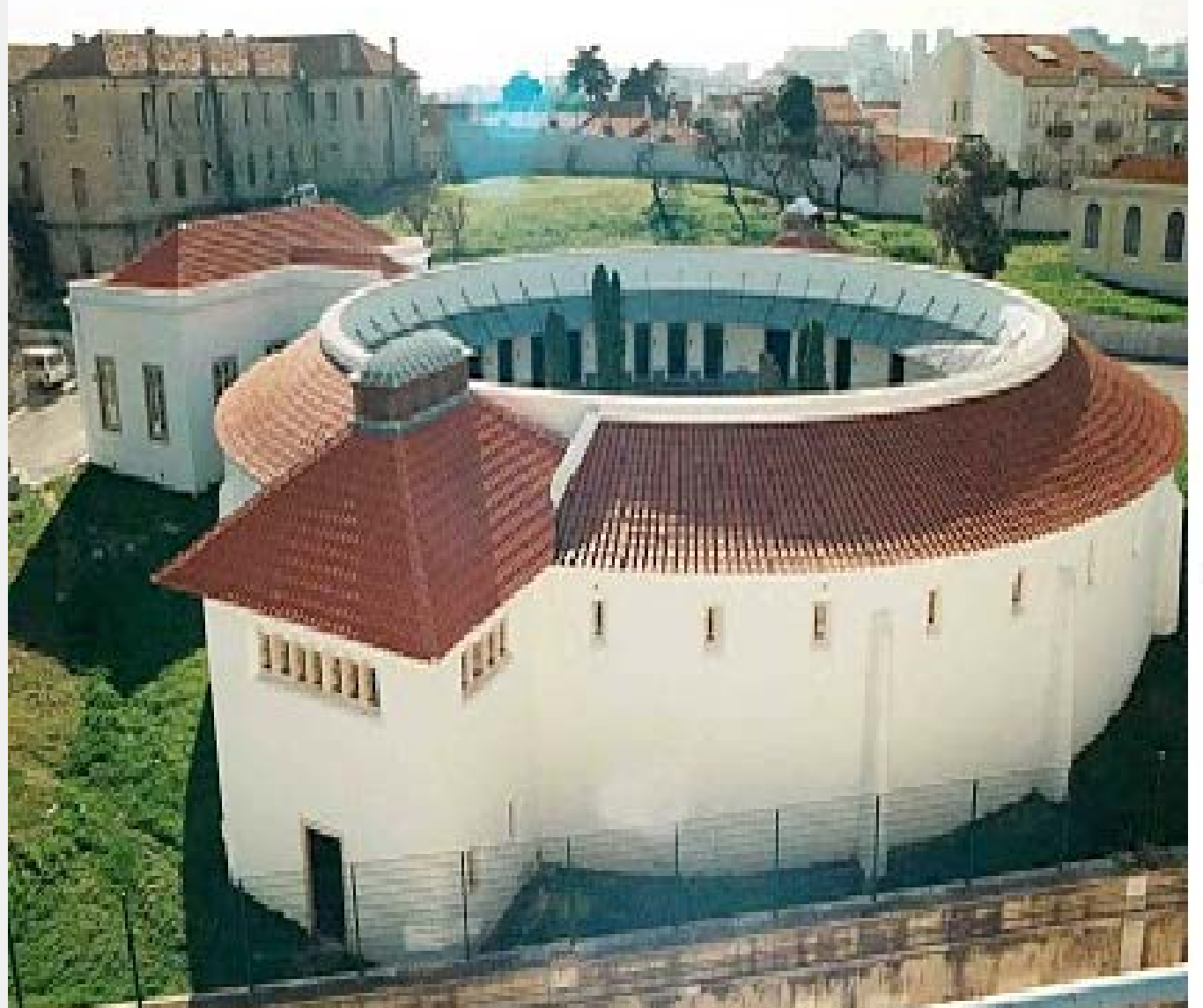

FIGURA 6

A questão da intersemioticidade nos permite refletir, entre outras coisas, sobre a relação entre as artes, possibilitando-nos estabelecer entre elas semelhanças e diferenças. Uma dessas possíveis reflexões diz respeito à delimitação daquilo que é próprio à literatura, como proposto por Maria Alzira Seixo: "O jogo intersemiótico desenvolve, sem dúvida,

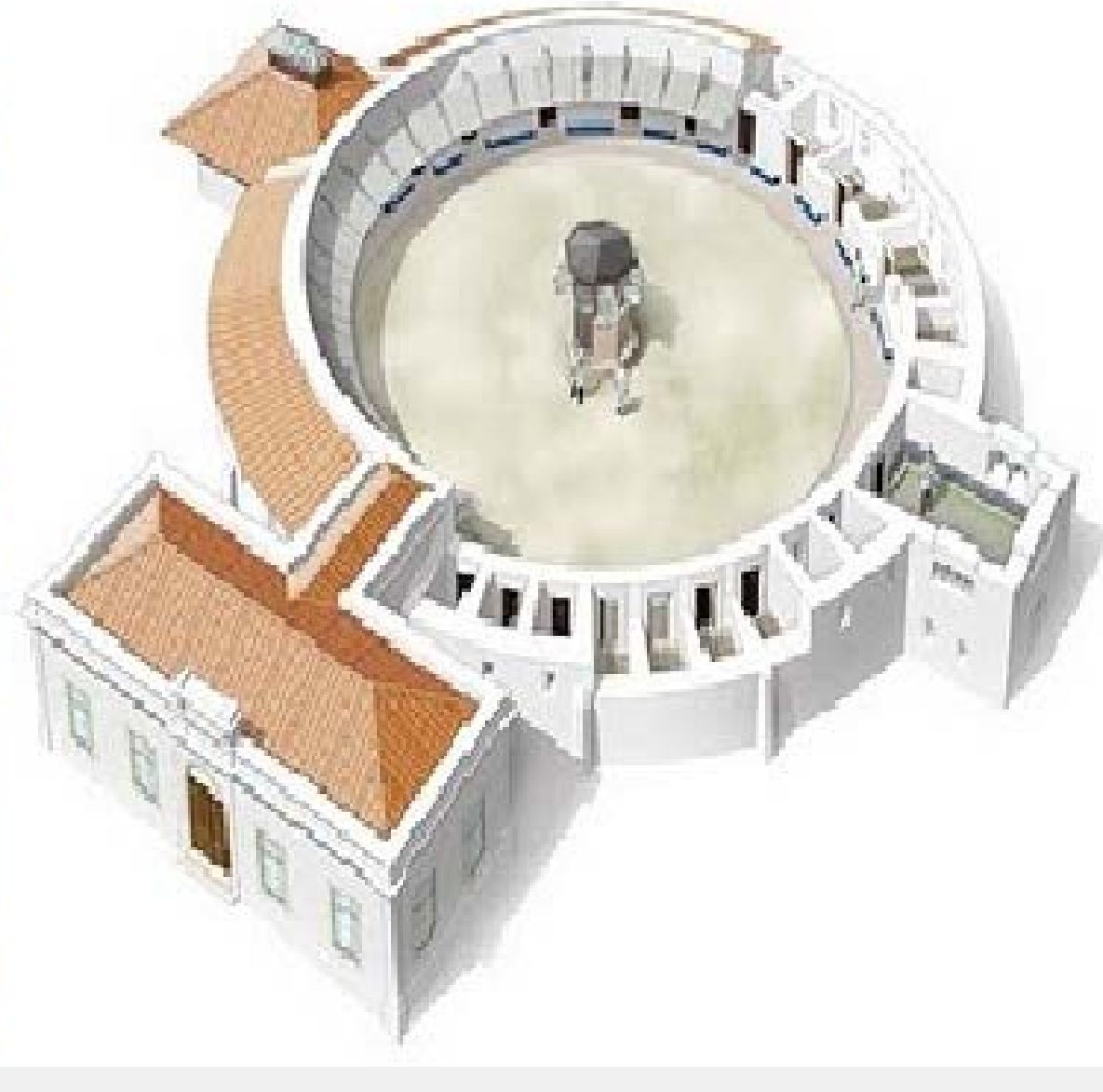

riqueza e variedade na escrita literária, comunicando-a na sua relação de sentido com arredores da criação que completam e lhe conferem, afinal, a especificidade". ${ }^{14}$ Em sua obra, Lobo Antunes estabelece diversas associações entre a literatura e outras formas de arte, demonstrando que, através da evocação de obras provenientes de outros meios expressivos, pode-se não só preencher possíveis lacunas do texto
14. SEIXO. Danças com Letras Intersemioticidade em António Lobo Antunes, p. 304 
escrito, como também evidenciar, de certa maneira, aspectos próprios de cada uma dessas artes.

\section{REFERÊNCIAS}

BIBLIOGRÁFICAS

ANTUNES, António Lobo. Memória de elefante. Rio de Janeiro: Objetiva, 2006

SEIXO, Maria Alzira. Danças com Letras - Intersemioticidade em António Lobo Antunes. In: As flores do inferno jardins suspensos. Lisboa: Dom Quixote, 2010. p. $281-304$.

\section{REFERÊNCIAS DOS QUADROS}

DELVAUX, Paul. The Village of Mermaids. Disponível em http:// www.artic.edu/aic/collections/artwork/74882. Acesso em 18 jul. 2012

GIACOMETTI, Alberto. Annette noire. Disponível em http:// oglobo.globo.com/cultura/giacometti-chega-ao-brasil-comomostra-mais-importante-de-2012-3618346. Acesso em 27 jun. 2012

GIACOMETTI, Alberto. Femme à l'épaule cassée. Disponível em http://www.sikart.ch/werke.aspx?id=12453890. Acesso em 9 jun 2012
MIRO, Joan. The Garden. Disponível em http://vi.sualize.us/ oan miro the garden blog painting picture nck7.html. Acesso em 24 jul. 2012.

MIRÓ, Joan. The Nightingale's Song at Midnight and the Morning Rain. Disponivel em http://www.abcgallery.com/M/miro/ miro61.html. Acesso em 18 jul. 2012.

SOUTINE, Chaïm. Paysage de Céret. Disponível em http://www. abcgallery.com/S/soutine/soutine10.html. Acesso em 21 jul. 2012.

VERMEER, Johannes. Girl with a pearl earring. Disponível

em http://en.wikipedia.org/wiki/File:Johannes Vermeer (16321675)_-_The_Girl_With_The_Pearl_Earring_(1665).jpg. Acesso em 21 jul. 2012.

\section{REFERENCIAS DAS IMAGENS}

HOSPITAL MIGUEL BOMBARDA (Imagem 1). Disponível em http://antonioalijo.blogspot.com.br/2011/01/arquitecto-earquitectito.html. Acesso em 21 jul. 2012

HOSPITAL MIGUEL BOMBARDA (Imagem 2). Disponível em http://laboratorio-cctp.blogspot.com.br/2010/04/memoria-econhecimento-pavilhao-de.html. Acesso em 21 jul. 2012. 